\title{
Using interval algebras to model order of magnitude reasoning
}

\author{
Simon Parsons
}

Department of Electronic Engineering, Queen Mary and Westfield College, Mile End Road, London E1 4NS, UK.

\begin{abstract}
Qualitative reasoning, introduced as a means of simulating human commonsense reasoning, has been extended by several authors to encompass reasoning about the order of magnitude of quantities. This paper discusses how interval algebras may form a basis for modelling three schemes for order of magnitude reasoning, and uses one of them to solve a problem from biotechnology.
\end{abstract}

Keywords: Order of magnitude reasoning, interval algebras, interval arithmetic, semiqualitative reasoning

\section{INTRODUCTION}

Complex physical systems are commonly described by sets of differential equations relating the behaviour of those key variables whose changes in value define the behaviour of the system as a whole. When solved these equations provide a model of the system which can be used to predict its behaviour under given circumstances. However, the solution of such sets of equations is often time-consuming, and the quality of the solution often depends upon the accuracy with which various constant terms are determined. Indeed it is impossible to perform a conventional computer based simulation of a complex system without such values. Human beings, in contrast, have little difficulty in performing reasoning such as "if pressure increases then volume decreases", and this sort of reasoning is possible even when the magnitude of some constants is only known relative to others, so that, for instance $K_{3}$ is known to be greater than $G_{m}$.

Qualitative reasoning ${ }^{1}$ was introduced as a formalism for reasoning about physical systems that captures many of these features of human reasoning. Qualitative reasoning reduces the quantitative precision of behavioural descriptions whilst retaining the crucial distinctions. Real valued variables are replaced with qualitative variables which can adopt only a small number of values, usually ,+ 0 and -. The behaviour is described in terms of changes in the qualitative value of a number of state variables and their first and second derivatives, and these values are related by means of qualitative differential equations, often called confluences. For example, we write:

$$
\begin{array}{cccc}
\mathrm{dP}_{\mathrm{IN}, \text { OUT }}+\mathrm{dQ}_{\# 1(\mathrm{~V}, \mathrm{~V})} & = & 0 \\
\mathrm{dP}_{\mathrm{OUT}, \mathrm{SMP}}+\mathrm{dF}_{\# 1(\mathrm{~S})}+\mathrm{dF}_{\mathrm{A}(\mathrm{M})} & = & 0 \\
\mathrm{dP}_{\mathrm{IN}, \text { SMP }} & + & &
\end{array}
$$

to qualitatively describe part of the behaviour of a pressure regulator, where $\mathrm{dP}$ is shorthand for $\mathrm{dP} / \mathrm{dt}$, the first time derivative of $\mathrm{P}$. In theory there is no reason to limit the information used to just the first two derivatives, but in practice it is extremely difficult to obtain higher order relations. All time derivatives are continuous, so that no variable may jump from one qualitative state to another without passing through any intervening states, and variables are combined by means of combinator tables giving the result of every possible combination of inputs, so for qualitative addition $\oplus$ we have the table of Figure 1 .

\begin{tabular}{|c|ccc|}
\hline$\oplus$ & + & 0 & - \\
\hline+ & + & + & $?$ \\
0 & + & 0 & - \\
- & $?$ & - & - \\
\hline
\end{tabular}

\section{Figure 1. Combinator table for qualitative addition}

The basic model has been extended in a number of directions in recent years, generally in an attempt to defeat its tendency to over abstract, obscuring important detail and rendering some simple problems insoluble. Notable attempts at providing more precise systems include Raiman's 2 FOG, Mavrovouniotis and Stephanopoulos'3 $\mathrm{O}[\mathrm{M}]$, and Dubois and Prade's ${ }^{4}$ system based on fuzzy arithmetic. These systems are often collectively known as order of magnitude systems since they make explicit use of the relative size between the quantities with which they deal.

Other important work has been carried out by TravéMassuyès and Piera ${ }^{5}$ who have provided a mathematical characterisation of some of the properties of order of magnitude models, and give a set of axioms for the algebras that they use. Struss 6 has provided an analysis of the soundness and completeness of qualitative models and has demonstrated that their difficulties in this respect are not alleviated by recasting them as algebras of more restricted intervals.

In this paper we briefly review the work of Raiman, Mavrovouniotis and Stephanopoulos, and Dubois and Prade. We introduce semiqualitative models as a generalisation of the basic qualitative calculus, and sketch their relationship with interval arithmetic ${ }^{7}$. Interval algebras are discussed as an extension of these ideas, and their relationship with Travé-Massuyès and Piera's qualitative algebras outlined. The main part of the paper analyses the ways in which interval and qualitative 
algebras may form a simple basis for order of magnitude reasoning.

\section{AN OVERVIEW OF ORDER OF MAGNITUDE TECHNIQUES}

There seem to be three distinct approaches to the formalisation of human order of magnitude reasoning; the process by which the relations between the magnitude of quantities is used to simplify the qualitative models used to predict the behaviour of devices and systems. Dubois and Prade ${ }^{4}$ showed that fuzzy set theory can provide a basis for an absolute order of magnitude system by dividing the real numbers into an arbitrarily large set of fuzzy intervals. Raiman ${ }^{2}$ proposed a system FOG that uses relational operators to denote the size relation between quantities. Finally, Mavrovouniotis and Stephanopoulos ${ }^{3}$ introduced a system $\mathrm{O}[\mathrm{M}]$ based on the relative magnitude of quantities that overcame what they saw as serious flaws in FOG.

In the remainder of this section we will briefly discuss the properties of these three approaches as a necessary precursor to demonstrating that interval arithmetic is capable of providing an underlying formal basis for the techniques.

\subsection{Absolute orders of magnitude and fuzzy intervals}

Dubois and Prade 4 propose that order of magnitude reasoning can be performed by increasing the precision of qualitative reasoning, splitting the quantity space ${ }^{1}\{-, 0$, + into smaller fuzzy intervals; negative large (NL), negative medium (NM), negative small (NS), zero (0), positive small (PS), positive medium (PM), positive large (PL). These may be viewed as a partitioning of the real numbers (Figure 2).

1

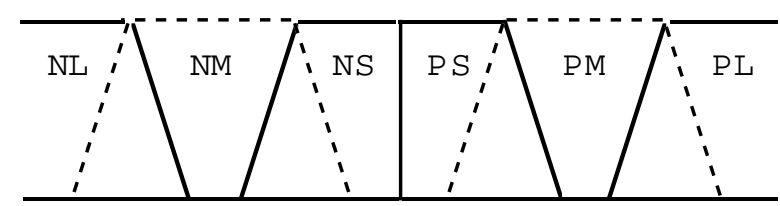

\section{Figure 2. A fuzzy partition of the real numbers}

It is suggested that a meaningful calculus should conform to the following conditions:

C1: The combinator tables which define the arithmetic operations of qualitative reasoning should be maintained for efficient order of magnitude reasoning.

C2: The calculus should be consistent with the real values that it approximates, and the operations over them.

Dubois and Prade show that the closure of the combinator tables for the fuzzy interval system can be obtained by defining the operations over all possible combinations of adjacent intervals in addition to the intervals themselves. Thus we have:

$\begin{array}{lll}\mathrm{PS} \oplus \mathrm{PS} & = & + \\ \mathrm{PM} \oplus \mathrm{PM} & = & \mathrm{PM}+ \\ \mathrm{PM} \oplus \mathrm{PL} & = & \mathrm{PL}\end{array}$

where $\oplus$ is the addition operator for the calculus, and $\mathrm{PM}+=[\mathrm{PM}, \mathrm{PL}],+=[\mathrm{PS}, \mathrm{PL}]$ for $\left[\mathrm{s}_{\mathrm{i}}, \mathrm{s}_{\mathrm{j}}\right]=\left\{\mathrm{s}_{\mathrm{k}} \mid \mathrm{s}_{\mathrm{i}} \leq \mathrm{s}_{\mathrm{k}}\right.$ $\left.\leq s_{j}\right\}$ with $s_{i}, s_{j}, s_{k} \in\{N L, N M, N S, 0, P S, P M, P L\}$.

\subsection{Relative orders of magnitude and $O[M]$}

Mavrovouniotis and Stephanopoulos ${ }^{3}$ constructed a system of order of magnitude reasoning based on seven primitive relations:
$\mathrm{A} \quad<\mathrm{B}$
A is much smaller than $\mathrm{B}$
$\mathrm{A}-<\mathrm{B} \quad \mathrm{A}$ is moderately smaller than $\mathrm{B}$
A $\sim$ B A is slightly smaller than B
$\mathrm{A}=\mathrm{B} \quad \mathrm{A}$ is exactly equal to $\mathrm{B}$
$\mathrm{A}>\sim \mathrm{B} \quad \mathrm{A}$ is slightly larger than B
$\mathrm{A}>-\mathrm{B} \quad \mathrm{A}$ is moderately larger than $\mathrm{B}$
A $>$ B A is much larger than B

Further relations are constructed as disjunctions of two or more consecutive relations, so that ' $\mathrm{A}$ is less than $\mathrm{B}$ ' is denoted ' $\mathrm{A}<<\ldots \sim<\mathrm{B}$ '. A total of 21 compound relations may be formed including all those that, Mavrovouniotis and Stephanopoulos claim, are commonly used by engineers.

The semantics of $\mathrm{O}[\mathrm{M}]$ relations are defined by fixing the allowed range of the ratio of the two quantities in question. We have for rel $\in\{<<,-<, \sim<,==,>\sim,>-,>>\}$ :

$$
\text { A rel B } \quad-\quad \frac{A}{B} \text { rel } 1
$$

and the bounds on the intervals are defined by the values $\mathrm{e}_{1}, \mathrm{e}_{2}, \mathrm{e}_{3}$, and $\mathrm{e}_{4}$ (see Figure 3(a)). A strict interpretation requires:

$$
\begin{array}{lll}
\mathrm{e}_{3} & = & \mathrm{e}_{1}+1 \\
\mathrm{e}_{4} & =\frac{1}{\mathrm{e}_{1}} \\
\mathrm{e}_{2} & =\frac{1}{\mathrm{e}_{3}}
\end{array}
$$

allowing the intervals to be determined by a single application specific accuracy parameter e (Figure 3 (b)):

$$
\mathrm{e}_{1} \quad \mathrm{e}
$$

This interpretation was felt to be too error prone, so the set of intervals was replaced with a pair of sets of overlapping (Figure 3 (c)) and non-exhaustive (Figure 3(d)) intervals, creating a so-called heuristic interpretation. Inferences proceed from antecedents whose values are restricted to the non-exhaustive intervals to create consequents that have overlapping interval values.

These consequent values are shrunk to non-exhaustive values when used as the basis for further reasoning. This 
behaviour mirrors the human tendency to chain approximate inferences regardless of the inherent uncertainty, reasoning that:

$$
\begin{array}{ll}
\mathrm{A}>\sim \mathrm{B}, \mathrm{B}>\sim \mathrm{C} \rightarrow & \mathrm{A}>\sim \mathrm{C} \\
\mathrm{A}>\sim \mathrm{C}, \mathrm{C}>\sim \mathrm{D} \rightarrow & \mathrm{A}>\sim \mathrm{D}
\end{array}
$$
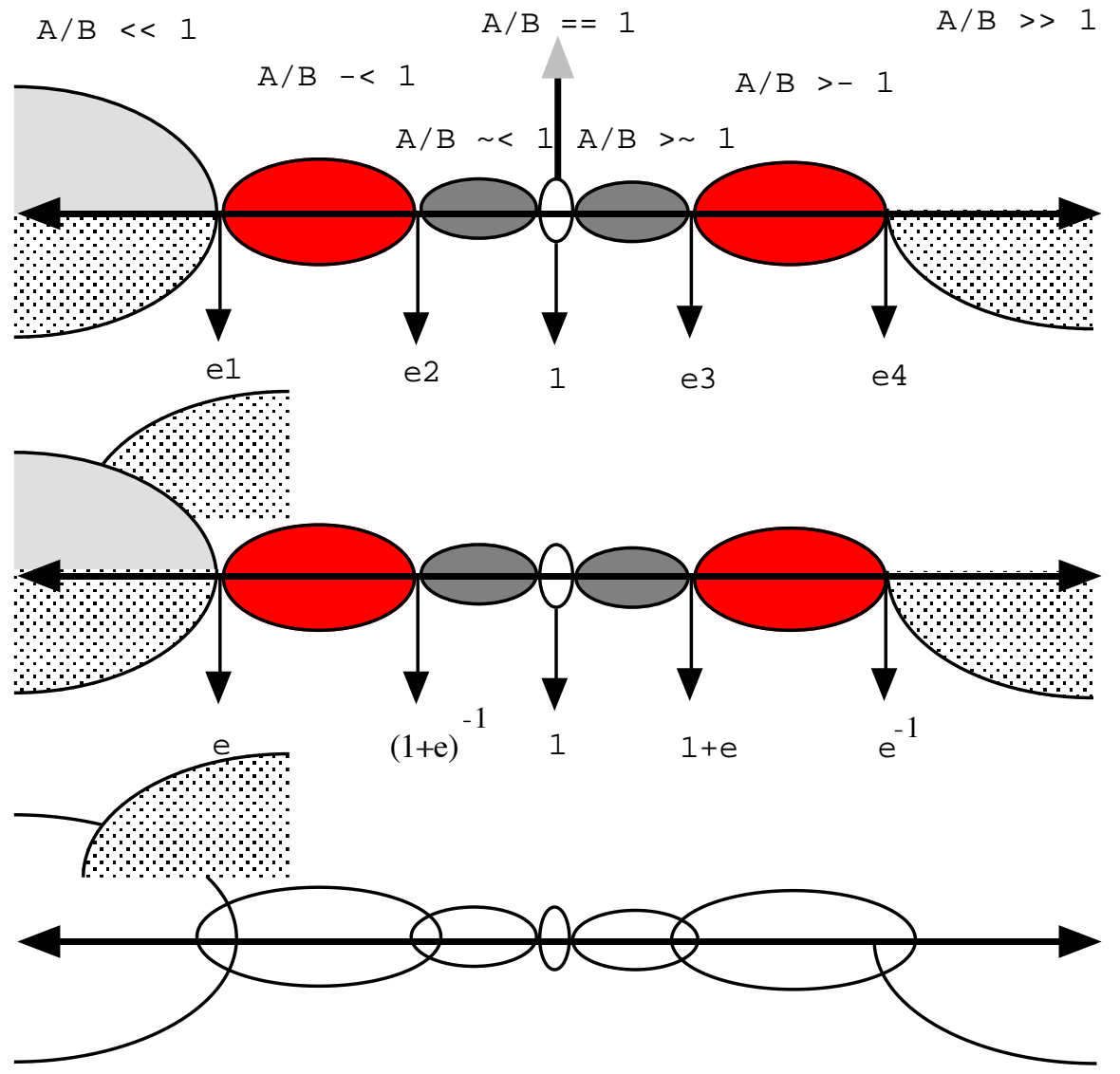

(c)

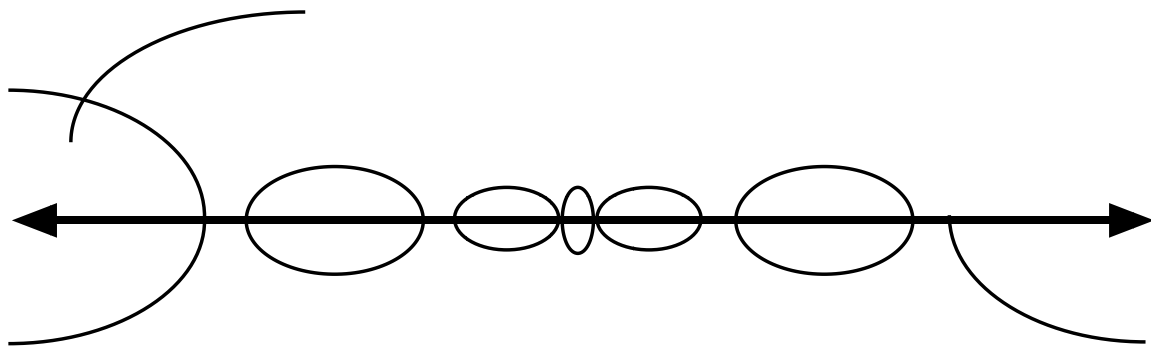

(d)

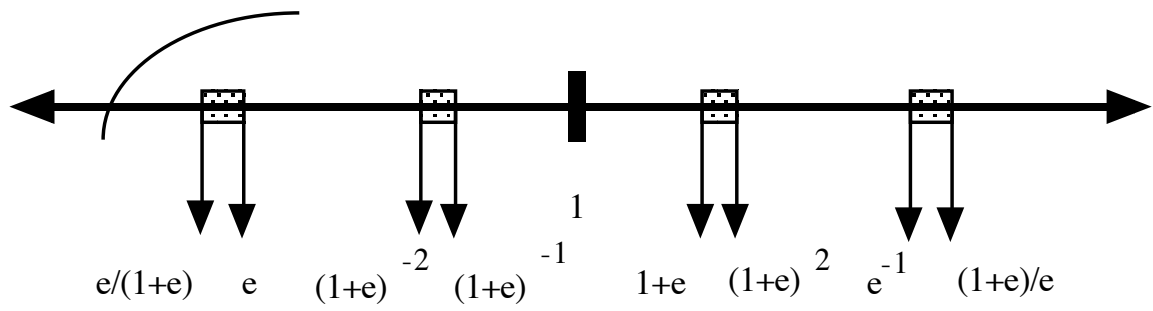

(e)

Figure 3. The intervals defining Mavrouniotis and Stephanopolous' primitive relations

The boundaries are those of Figure 3(e).

2.3 FOG and Symbolic relations
Raiman $^{2}$ introduced the FOG system based on three operators, Ne, Vo, Co representing what he claimed were intuitive order of magnitude concepts:

A Ne B : A is negligible with respect to B 
A Vo B : A is close to B so that A - B is negligible with respect to $B$

A Co B : A is comparable to B so that $\mathrm{A}$ has the same sign and order of magnitude as $\mathrm{B}$ so that if $\mathrm{B}$ $\mathrm{Ne} \mathrm{C}$, then A Ne C.

these relations are used to define a set of 31 inference rules such as:

$\begin{array}{lll}\text { A Vo B } & \rightarrow & \text { B Vo A } \\ \text { A Vo B, B VoC } & \rightarrow & \text { A Vo C } \\ \text { A Ne B, B NeC } & \rightarrow & \text { A Ne C } \\ \text { A Vo B, B NeC } & \rightarrow & \text { A NeC }\end{array}$

and the rules are then used with the axiom A Vo A to propagate relations between quantities to solve problems that defeat qualitative reasoning due to the latter's over abstraction.

Raiman provides a semantics for the relations based on non-standard analysis. As Dubois and $\operatorname{Prade}^{8}$ point out, while this is natural in the limiting case, it is problematic when relations such as 'close' are taken to mean 'within a certain interval' rather than 'infinitely close'. Indeed, such an interpretation makes the transitivity of $\mathrm{Vo}_{\mathrm{o}}$ unacceptable, and forces Raiman to limit the repeated use of such rules.

Dubois and Prade ${ }^{4}$ suggest using fuzzy relations to model the FOG approach to order of magnitude reasoning, giving a fuzzy interpretation of the symbolic relations.

\section{A FAMILY OF INTERVAL ALGEBRAS}

In this section we discuss semiqualitative reasoning ${ }^{9}$ as an implementation of interval arithmetic ${ }^{7}$ and show how interval algebras may be defined. The relationship between interval algebras and the qualitative algebra of TravéMassuyès and Piera 5 is outlined.

\subsection{Interval arithmetic and semiqualitative reasoning}

Semiqualitative reasoning is a generalisation of qualitative reasoning 1 which increases precision by splitting the quantity space into $(2 \mathrm{k}+1)$ intervals whose boundaries are the ordered set of values:

$$
\left\{\mathrm{I}_{(-\mathrm{k})}, \mathrm{I}_{(-(\mathrm{k}-1)}, \ldots, \mathrm{I}_{(-1)}, \mathrm{I}_{(0)}, \mathrm{I}_{(1)}, \ldots, \mathrm{I}_{(\mathrm{k}-1)}, \mathrm{I}_{(\mathrm{k})}\right\}
$$

where $I_{(+j)}$ is the upper boundary of the $j$ th positive interval, $I_{(-j)}$ is the lower boundary of the $j$ th negative interval and $\mathrm{I}_{(0)}$ is the zero interval. Clearly the standard quantity space $\{+, 0,1\}$ is that obtained for $\mathrm{k}=1, \mathrm{I}_{(-\mathrm{k})}=$ - and $\mathrm{I}_{(\mathrm{k})}=\bullet$.

The size of the intervals is tailored to suit specific problems, and the sequence of boundaries may be in an arithmetic or geometric progression, or chosen to cover values of interest ${ }^{9}$. The arithmetic properties of semiqualitative systems are defined by Moore's interval arithmetic, and are summarised by: $[\mathrm{a}, \mathrm{b}] \otimes_{\mathrm{i}}[\mathrm{c}, \mathrm{d}]=\left[\min \left(\mathrm{a} \otimes_{\mathrm{j}} \mathrm{c}, \mathrm{a} \otimes_{\mathrm{j}} \mathrm{d}, \mathrm{b} \otimes_{\mathrm{j}} \mathrm{c}, \mathrm{b} \otimes_{\mathrm{j}} \mathrm{d}\right\}\right.$,

$$
\left.\max \left(a \otimes_{j} c, a \otimes_{j} d, b \otimes_{j} c, b \otimes_{j} d\right)\right]
$$

where $\otimes_{\mathrm{j}} \in\{+,-, \times, \div\}$ and $\otimes_{\mathrm{i}}$ is its interval equivalent. Division by intervals containing 0 is not defined. Note that operations over degenerate intervals [a, b] where $a=b$, are equal to the equivalent operations over the respective reals:

$$
[a, b] \otimes_{i}[c, d]=a \otimes_{j} c=a \otimes_{j} d=b \otimes_{j} c=b \otimes_{j} d
$$

for $\mathrm{a}=\mathrm{b}$ and $\mathrm{c}=\mathrm{d}$. Thus interval arithmetic may be considered to be a generalisation of real arithmetic. In practice the results of arithmetic operations are specified by means of combinator tables. Consider a system using the ordered set of intervals $\{[a, b],[b, c],[c, d]\}$ with equal spacing so that $(b-a)=(c-b)=(d-c)$ and $d=3 b$. The tendency of interval arithmetic to extend the interval bounds means that the full set of operands include compound intervals, so that the operator table for addition $\oplus$ is that of Figure 4 .

The closure of the operations is clearly a problem for arbitrarily specified intervals. A suitable approximation may be, as above, to allow the upper and lower intervals to absorb all values that exceed their bounds.

\begin{tabular}{|c|cccccc|}
\hline$\oplus$ & {$[\mathrm{a}, \mathrm{b}]$} & {$[\mathrm{a}, \mathrm{c}]$} & {$[\mathrm{a}, \mathrm{d}]$} & {$[\mathrm{b}, \mathrm{c}]$} & {$[\mathrm{b}, \mathrm{d}]$} & {$[\mathrm{c}, \mathrm{d}]$} \\
\hline$[\mathrm{a}, \mathrm{b}]$ & {$[\mathrm{a}, \mathrm{c}]$} & {$[\mathrm{a}, \mathrm{d}]$} & {$[\mathrm{a}, \mathrm{d}]$} & {$[\mathrm{b}, \mathrm{d}]$} & {$[\mathrm{b}, \mathrm{d}]$} & {$[\mathrm{c}, \mathrm{d}]$} \\
{$[\mathrm{a}, \mathrm{c}]$} & {$[\mathrm{a}, \mathrm{d}]$} & {$[\mathrm{a}, \mathrm{d}]$} & {$[\mathrm{a}, \mathrm{d}]$} & {$[\mathrm{b}, \mathrm{d}]$} & {$[\mathrm{b}, \mathrm{d}]$} & {$[\mathrm{c}, \mathrm{d}]$} \\
{$[\mathrm{a}, \mathrm{d}]$} & {$[\mathrm{a}, \mathrm{d}]$} & {$[\mathrm{a}, \mathrm{d}]$} & {$[\mathrm{a}, \mathrm{d}]$} & {$[\mathrm{b}, \mathrm{d}]$} & {$[\mathrm{b}, \mathrm{d}]$} & {$[\mathrm{c}, \mathrm{d}]$} \\
{$[\mathrm{b}, \mathrm{c}]$} & {$[\mathrm{b}, \mathrm{d}]$} & {$[\mathrm{b}, \mathrm{d}]$} & {$[\mathrm{b}, \mathrm{d}]$} & {$[\mathrm{b}, \mathrm{d}]$} & {$[\mathrm{b}, \mathrm{d}]$} & {$[\mathrm{c}, \mathrm{d}]$} \\
{$[\mathrm{b}, \mathrm{d}]$} & {$[\mathrm{b}, \mathrm{d}]$} & {$[\mathrm{b}, \mathrm{d}]$} & {$[\mathrm{b}, \mathrm{d}]$} & {$[\mathrm{b}, \mathrm{d}]$} & {$[\mathrm{b}, \mathrm{d}]$} & {$[\mathrm{c}, \mathrm{d}]$} \\
{$[\mathrm{c}, \mathrm{d}]$} & {$[\mathrm{c}, \mathrm{d}]$} & {$[\mathrm{b}, \mathrm{d}]$} & {$[\mathrm{c}, \mathrm{d}]$} & {$[\mathrm{c}, \mathrm{d}]$} & {$[\mathrm{c}, \mathrm{d}]$} & {$[\mathrm{c}, \mathrm{d}]$} \\
\hline
\end{tabular}

Figure 4. The combinator table for the addition of a set of intervals

This is unlikely to appeal to purists, and an alternative approach is to consider new maximum and minimum intervals extending from the largest positive and negative values to $\pm \bullet$. Despite such theoretical problems, semiqualitative techniques have been successfully applied to number of engineering problems which are not soluble by pure qualitative reasoning. Such problems include simulations of chemical reactions ${ }^{10}$ and bioengineering processes $^{11}$.

\subsection{Interval and Qualitative Algebras}

A particular interval algebra may be defined from a ordered set of values $\mathrm{V}=\left\{\mathrm{v}_{1}, \ldots, \mathrm{v}_{\mathrm{n}}\right\}$. The set of intervals over which the operators of the algebra are closed is the set of all intervals $\left[\mathrm{v}_{\mathrm{i}}, \mathrm{v}_{\mathrm{j}}\right]$ such that $\mathrm{v}_{\mathrm{i}} \leq \mathrm{v}_{\mathrm{j}}$ and $\mathrm{v}_{\mathrm{i}}, \mathrm{v}_{\mathrm{j}} \in \mathrm{V}$. We can define an order ${ }^{12} \leq{ }_{\mathrm{Q} 3}$ over the interval such that $\left[\mathrm{v}_{\mathrm{i}}\right.$, $\left.\mathrm{v}_{\mathrm{j}}\right] \leq_{\mathrm{Q} 3}\left[\mathrm{v}_{\mathrm{k}}, \mathrm{v}_{\mathrm{l}}\right]$ iff $\left(\mathrm{v}_{\mathrm{i}}+\mathrm{v}_{\mathrm{j}}\right) \leq\left(\mathrm{v}_{\mathrm{k}}+\mathrm{v}_{\mathrm{l}}\right)$. 
Travé-Massuyès and Piera $^{5}$ present a mathematical framework to support order of magnitude reasoning that explicitly distinguishes between different levels of description. Given a set $\mathrm{S}$ and an order $\leq$ defined over $\mathrm{S}$, qualitative equality \pm is defined as:

$\mathrm{a} \pm \mathrm{b}$ if there exists $\mathrm{x} \in \mathrm{S}$ such that $\mathrm{x} \leq \mathrm{a}$ and $\mathrm{x} \leq \mathrm{b}$.

A qualitative algebra is a pair $(S, \pm)$ provided with operations $\oplus$ and $\otimes$, which are:

(i) qualitatively associative: $\mathrm{a} \otimes(\mathrm{b} \otimes \mathrm{c}) \pm(\mathrm{a} \otimes \mathrm{b}) \otimes \mathrm{c}$ and $\mathrm{a} \oplus(\mathrm{b} \oplus \mathrm{c}) \pm(\mathrm{a} \oplus \mathrm{b}) \oplus \mathrm{c}$.

(ii) qualitatively commutative: $\mathrm{a} \otimes \mathrm{b} \pm \mathrm{b} \otimes \mathrm{a}$ and $\mathrm{a} \oplus \mathrm{b}$ $\pm \mathrm{b} \oplus \mathrm{a}$.

(iii) $\otimes$ is qualitatively distributive with respect to $\oplus: \mathrm{a} \otimes$ $(\mathrm{b} \oplus \mathrm{c}) \pm(\mathrm{a} \otimes \mathrm{b}) \oplus(\mathrm{a} \otimes \mathrm{c})$.

Travé-Massuyès and Piera prove that a qualitative algebra $(\mathrm{S}, \pm, \oplus, \otimes)$ and a subalgebra $(\mathrm{T}, \pm, \oplus, \otimes)$ where $\mathrm{T}<\mathrm{S}$ and $\mathrm{T} \neq \varnothing$ are embedded in one another, and that it is possible to dynamically refine a model during processing by switching from $\mathrm{T}$ to $\mathrm{S}$.

It is possible to show ${ }^{9}$ that interval algebras defined as above are qualitative algebras $\left(S_{i}, \pm, \oplus, \otimes\right)$ for interval addition $\oplus$, interval multiplication $\otimes$, and Q-equality defined by the following:

$\left[\mathrm{v}_{1}-\mathrm{v}_{\mathrm{j}}\right] \pm\left[\mathrm{v}_{\mathrm{k}}-\mathrm{v}_{\mathrm{i}}\right]$ if there exists an interval $\left[\mathrm{v}_{\mathrm{a}}, \mathrm{v}_{\mathrm{b}}\right]$ such that $\left[\mathrm{v}_{\mathrm{a}}, \mathrm{v}_{\mathrm{b}}\right] \leq_{\mathrm{Q} 3}\left[\mathrm{v}_{\mathrm{i}}, \mathrm{v}_{\mathrm{j}}\right]$ and $\left[\mathrm{v}_{\mathrm{a}}, \mathrm{v}_{\mathrm{b}}\right] \mathrm{s}_{\mathrm{Q} 3}\left[\mathrm{v}_{\mathrm{k}}\right.$, $\left.\mathrm{v}_{1}\right]$.

\section{ORDER OF MAGNITUDE REASONING USING INTERVALS}

Having discussed several proposals for order of magnitude reasoning in some detail, we now demonstrate how they may be interpreted in terms of interval algebras. Whilst interval methods may be said to subsume FOG and O[M] in some sense, it makes little sense to claim that it subsumes the more general fuzzy approach. Instead we can merely claim that the full mechanism of fuzzy mathematics is not required for the comparatively simple domain discussed by Dubois and Prade.

\subsection{Absolute order of magnitude}

As suggested by Dubois and Prade, their absolute order of magnitude scheme may be modelled by adjacent intervals.
In keeping with the underlying interval arithmetic, we will reference the intervals by their endpoints so that $\mathrm{NL}=$ $[-\bullet, \mathrm{nm}], \mathrm{NM}=[\mathrm{nm}, \mathrm{ns}], \mathrm{NS}=[\mathrm{ns}, 0], \mathrm{PS}=[0, \mathrm{ps}], \mathrm{PM}$ $=[\mathrm{ps}, \mathrm{pm}]$ and $\mathrm{PL}=[\mathrm{pm}, \bullet]$. This gives the intervals of Figure 5.

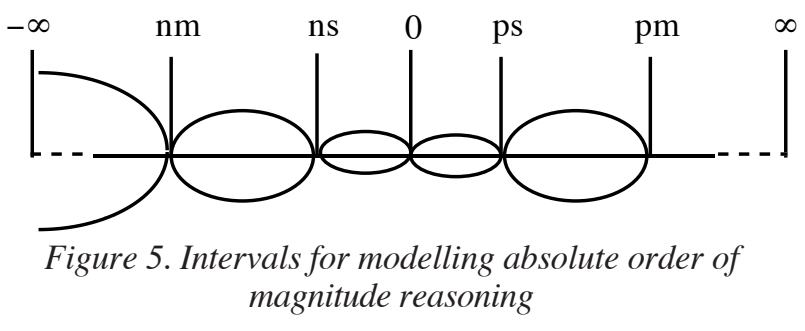

Defining the intervals by means of their boundaries gives us an easy means of obtaining closure, since the operations over two intervals are defined by equation (3). The additional intervals are formed automatically, and follow directly from the set of landmark values. The combinator table for the addition operation $\oplus$ includes Figure 6 for the addition of positive valued intervals.

With the full $\oplus$ table, and a combinator table for interval multiplication $\otimes$ as defined by (3) we can specify a family $\mathrm{S}$ of algebras over the basic set of intervals $\{[-$ $\infty, \mathrm{nm}],[\mathrm{nm}, \mathrm{ns}],[\mathrm{ns}, 0],[0, \mathrm{ps}],[\mathrm{ps}, \mathrm{pm}],[\mathrm{pm}, \infty]\}$ such that $<\mathrm{S}_{\mathrm{i}}, \pm, \oplus, \otimes>\in \mathrm{S}$ and $\mathrm{S}_{\mathrm{i}} /\{\{[-\infty, \mathrm{nm}],[\mathrm{nm}$, $\mathrm{ns}],[\mathrm{ns}, 0],[0, \mathrm{ps}],[\mathrm{ps}, \mathrm{pm}],[\mathrm{pm}, \infty]\},\{[-\infty, \mathrm{ns}],[\mathrm{nm}$, $0]$, [ns, ps], [pm, 0], [ps, $\infty]\},\{[-\infty, 0],[\mathrm{nm}, \mathrm{ps}],[\mathrm{ns}$, $\mathrm{pm}],[0, \infty]\},\{[-\infty, \mathrm{ps}],[\mathrm{nm}, \mathrm{pm}],[\mathrm{ns}, \infty]\}\{[-\infty, \mathrm{pm}]$, $[\mathrm{nm}, \infty]\},\{[-\infty, \infty]\}\}$. Note that the intervals $[0, \infty]$ and $[-\infty, 0]$ correspond to the qualitative intervals + and respectively, and that $[-\infty, \infty]$ is equivalent to the qualitative value ? introduced to maintain closure ${ }^{1}$. There is an implied order on the $S_{i}$ that is summarised by Figure 7.

Since the family $\mathrm{S}$ are interval algebras and thus obey Travé-Massuyès and Piera's axioms, we can switch between levels of granularity at will.

It is also possible to consider the fuzzy intervals as defining overlapping intervals on the real axis. This interpretation may also be modelled using adjacent 


\begin{tabular}{|c|cccccccc|}
\hline$\oplus$ & {$[0, p s]$} & {$[0, p m]$} & {$[0, \cdot]$} & {$[p s, p m]$} & {$[p s, \cdot]$} & {$[p m, \cdot]$} \\
\hline$[0, p s]$ & {$[0, \cdot]$} & {$[0, \cdot]$} & {$[0, \cdot]$} & {$[p s, \cdot]$} & {$[p s, \cdot]$} & {$[p m, \cdot]$} \\
{$[0, p m]$} & {$[0, \cdot]$} & {$[0, \cdot]$} & {$[0, \cdot]$} & {$[p s, \cdot]$} & {$[p s, \cdot]$} & {$[p m, \cdot]$} \\
{$[0, \cdot]$} & {$[0, \cdot]$} & {$[0, \cdot]$} & {$[0, \cdot]$} & {$[p s, \cdot]$} & {$[p s, \cdot]$} & {$[p m, \cdot]$} \\
{$[p s, p m]$} & {$[p s, \cdot]$} & {$[p s, \cdot]$} & {$[p s, \cdot]$} & {$[p s, \cdot]$} & {$[p s, \cdot]$} & {$[p m, \cdot]$} \\
{$[p s, \cdot]$} & {$[p s, \cdot]$} & {$[p s, \cdot]$} & {$[p s, \cdot]$} & {$[p s, \cdot]$} & {$[p s, \cdot]$} & {$[p m, \cdot]$} \\
{$[p m, \cdot]$} & {$[p m, \cdot]$} & {$[p m, \cdot]$} & {$[p m, \cdot]$} & {$[p m, \cdot]$} & {$[p m, \cdot]$} & {$[p m, \cdot]$} \\
\hline
\end{tabular}

Figure 6. Part of the combinator table for addition of Dubois and Prade's set of intervals

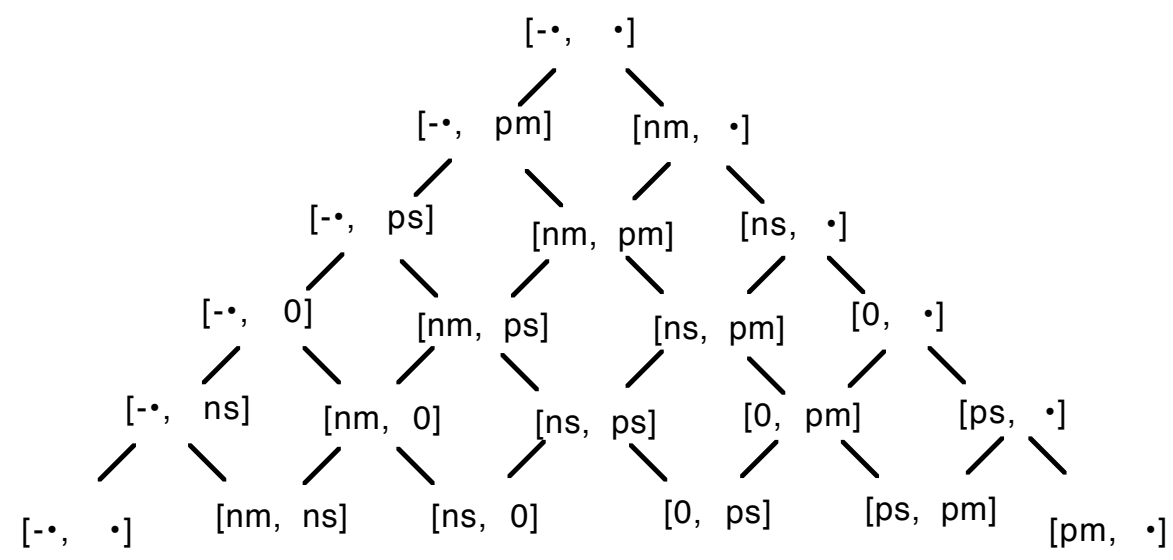

Figure 7. The order on the family of algebras

intervals by distinguishing between those regions that are, say, purely in PM, and those that are in PS and PM or PL and PM. Such an interpretation is given in Figure 8. Here $\mathrm{NL}=[-\infty, \mathrm{nm}-], \mathrm{NM}=[\mathrm{nm}+, \mathrm{ns}-], \mathrm{NS}=[\mathrm{ns}+, 0], \mathrm{PS}=$ $[0, \mathrm{ps}+], \mathrm{PM}=[\mathrm{ps}-, \mathrm{pm}+]$ and $\mathrm{PL}=[\mathrm{pm}-, \infty]$. A further family of interval algebras may be based on this set of values.

\subsection{Relative order of magnitude models}

Here we discuss how we can interpret quantities in terms of the $\mathrm{O}[\mathrm{M}]$ model. We can both propagate interval values, and deal with order of magnitude relations, which are essentially interval based, between relations.

\subsubsection{The strict interpretation}

$\mathrm{O}[\mathrm{M}]$ relations are defined by means of the interval containing the result of dividing one quantity by another. Thus the representation has an natural interval arithmetic interpretation. We first define a mapping [[ ]] between the ratio between the quantities and their $\mathrm{O}[\mathrm{M}]$ relation. For any $A=\left[a_{1}, a_{2}\right] B=\left[b_{1}, b_{2}\right]$ :

$$
[[\mathrm{A} B]]= \begin{cases}\mathrm{A}<<\mathrm{B} & \text { if } \mathrm{e}_{1}>[\mathrm{A} / \mathrm{B} \\ \mathrm{A}-<\mathrm{B} & \text { if } \mathrm{e}_{1}<[\mathrm{A} / \mathrm{B}]<\mathrm{e}_{2} \\ \mathrm{~A} \sim \mathrm{B} & \text { if } \mathrm{e}_{2}<[\mathrm{A} / \mathrm{B}]<1 \\ \mathrm{~A}==\mathrm{B} & \text { if } 1=[\mathrm{A} / \mathrm{B}] \\ \mathrm{A}>\sim \mathrm{B} & \text { if } 1<[\mathrm{A} / \mathrm{B}]<\mathrm{e}_{3} \\ \mathrm{~A}>-\mathrm{B} & \text { if } \mathrm{e}_{3}<[\mathrm{A} / \mathrm{B}]<\mathrm{e}_{4} \\ \mathrm{~A}>>\mathrm{B} & \text { if } \mathrm{e}_{4}<[\mathrm{A} / \mathrm{B}]\end{cases}
$$

where $[A / B]=\left[a_{1} / b_{2}, a_{2} / b_{1}\right]$ is the interval valued result of dividing $\mathrm{A}$ by $\mathrm{B}$.

The mapping loses no generality by being described as operating over intervals (see Section 3.1) and the interval definition will be required to establish the result of order of magnitude inference. The constants $\mathrm{e}_{1}, \mathrm{e}_{2}, \mathrm{e}_{3}$ and $\mathrm{e}_{4}$ are related to the accuracy parameter e by (1) and (2). A reverse mapping [[ ]]' generates the permitted interval value of $\mathrm{A} / \mathrm{B}$ from the relation between them. For rel $\in$ $\{<<,-<, \sim<,==,>\sim,>-,>>\}, A=\left[a_{1}, a_{2}\right] B=\left[b_{1}, b_{2}\right]$, and $[\mathrm{A} / \mathrm{B}]=\left[\mathrm{a}_{1} / \mathrm{b}_{2}, \mathrm{a}_{2} / \mathrm{b}_{1}\right]$ : 


$$
\left[\left[\text { A rel B]] }= \begin{cases}\mathrm{e}_{1}>[\mathrm{A} / \mathrm{B}] & \text { if rel }=<< \\ \mathrm{e}_{1}<[\mathrm{A} / \mathrm{B}]<\mathrm{e}_{2} & \text { if rel }=-< \\ \mathrm{e}_{2}<[\mathrm{A} / \mathrm{B}]<1 & \text { if rel }=\sim< \\ 1=[\mathrm{A} / \mathrm{B}] & \text { if rel }=== \\ 1<[\mathrm{A} / \mathrm{B}]<\mathrm{e}_{3} & \text { if rel }=>\sim \\ \mathrm{e}_{3}<[\mathrm{A} / \mathrm{B}]<\mathrm{e}_{4} & \text { if rel }=>- \\ \mathrm{e}_{4}<[\mathrm{A} / \mathrm{B}] & \text { if rel }=>>\end{cases}\right.\right.
$$

Initial relations between quantities may established either by [[ ]] or by definition. Propagation is achieved by using [[ ]] to get the bounds on the ratios between quantities which are then manipulated using interval arithmetic. [[ ]] is then applied to obtain the final relations. Thus given $\mathrm{A}$ $-<\mathrm{B}$ and $\mathrm{B}-<\mathrm{C}$ we can use [[ ]]' to obtain $\mathrm{e}_{1}<[\mathrm{A} / \mathrm{B}]<$ $\mathrm{e}_{2}$ and $\mathrm{e}_{1}<[\mathrm{B} / \mathrm{C}]<\mathrm{e}_{2}$ from which it is trivial to establish $\mathrm{e}_{1}{ }^{2}<[\mathrm{A} / \mathrm{C}]<\mathrm{e}_{2}{ }^{2}$. This interval ratio can be converted by [[]] into the relationship $\mathrm{A}<<\ldots-<\mathrm{C}$. The extension of the interval mirrors the cautious, and arguably correct, tendency of interval arithmetic to accentuate the underlying uncertainty. Given the bounds on $-<$ it is possible that the value of $\mathrm{A} / \mathrm{C}$ is less than the lower limit on $-<$

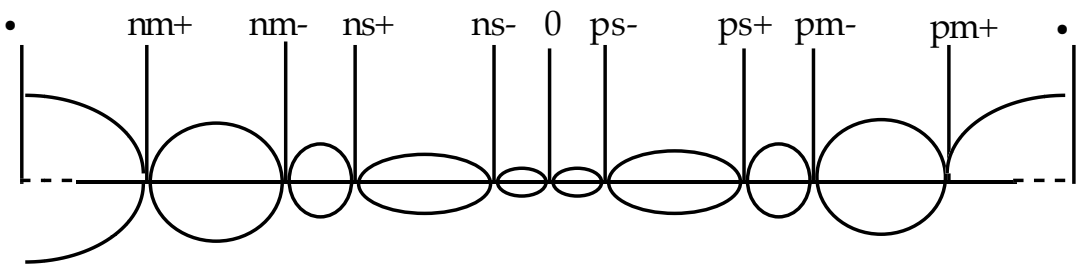

Figure 8. An alternative modelling of absolute order of magnitude reasoning

\subsubsection{The heuristic interpretation}

If such cautious inferences are to be avoided we must support the heuristic interpretation, which requires another pair of mappings; [[ ] ] $]_{\mathrm{h}}$ to map onto the extended intervals, and $[[]]_{\mathrm{h}}$ ' to retrieve the non-exhaustive intervals. So for $A=\left[a_{1}, a_{2}\right] \quad B=\left[b_{1}, b_{2}\right]$ and $[A / B]=$ $\left[\mathrm{a}_{1} / \mathrm{b}_{2}, \mathrm{a}_{2} / \mathrm{b}_{1}\right]$ :

$$
[[\mathrm{AB}]]_{\mathrm{h}}= \begin{cases}\mathrm{A}<<\mathrm{B} & \text { if } \mathrm{e}_{1}>[\mathrm{A} / \mathrm{B}] \\ \mathrm{A}-<\mathrm{B} & \text { if } \mathrm{e}_{5}<[\mathrm{A} / \mathrm{B}]<\mathrm{e}_{2} \\ \mathrm{~A} \sim<\mathrm{B} & \text { if } \mathrm{e}_{6}<[\mathrm{A} / \mathrm{B}]<1 \\ \mathrm{~A}==\mathrm{B} & \text { if } 1=[\mathrm{A} / \mathrm{B}] \\ \mathrm{A}>\sim \mathrm{B} & \text { if } 1<[\mathrm{A} / \mathrm{B}]<\mathrm{e}_{3} \\ \mathrm{~A}>\sim \mathrm{B} & \text { if } \mathrm{e}_{7}<[\mathrm{A} / \mathrm{B}]<\mathrm{e}_{4} \\ \mathrm{~A}>>\mathrm{B} & \text { if } \mathrm{e}_{8}<[\mathrm{A} / \mathrm{B}]\end{cases}
$$

where $\mathrm{e}_{1}, \mathrm{e}_{2}, \mathrm{e}_{3}$ and $\mathrm{e}_{4}$ are related to e by (1) and (2), and $\mathrm{e}_{5}=\mathrm{e} /(1+\mathrm{e}), \mathrm{e}_{6}=(1+\mathrm{e})^{-2}, \mathrm{e}_{7}=(1+\mathrm{e})^{2}$, and $\mathrm{e}_{8}=(1+$ e)/e are the boundaries of the interval overlaps. We also have, for any A, B, rel:

$$
[[\text { A rel } \mathrm{B}]]_{\mathrm{h}},= \begin{cases}\mathrm{e}_{5}>[\mathrm{A} / \mathrm{B}] & \text { if rel }=<< \\ \mathrm{e}_{1}<[\mathrm{A} / \mathrm{B}]<\mathrm{e}_{6} & \text { if rel }=-< \\ \mathrm{e}_{2}<[\mathrm{A} / \mathrm{B}]<1 & \text { if rel }=\sim< \\ 1=[\mathrm{A} / \mathrm{B}] & \text { if rel }=== \\ 1<[\mathrm{A} / \mathrm{B}]<\mathrm{e}_{3} & \text { if rel }=>\sim \\ \mathrm{e}_{7}<[\mathrm{A} / \mathrm{B}]<\mathrm{e}_{4} & \text { if rel }=>- \\ \mathrm{e}_{8}<[\mathrm{A} / \mathrm{B}] & \text { if rel }=>>\end{cases}
$$

using the same procedure as before we can take $\mathrm{A} \sim<\mathrm{B}$ and $\mathrm{B} \sim<\mathrm{C}$, obtain $(1+\mathrm{e})^{-1}<[\mathrm{A} / \mathrm{B}]<1$ and $(1+\mathrm{e})^{-1}<$
$[\mathrm{B} / \mathrm{C}]<1$ from which we deduce $(1+\mathrm{e})^{-2}<[\mathrm{A} / \mathrm{C}]<1$ which enables us to conclude that $\mathrm{A} \sim<\mathrm{C}$.

Note that while the mappings given here cover just the basic $\mathrm{O}[\mathrm{M}]$ relations, there is no reason why they cannot be extended to deal with all 21 compound relations. For instance we can define $[[\mathrm{A} \mathrm{B}]]=\mathrm{A}-<\ldots \sim<\mathrm{B}$ if $\mathrm{e}_{1}<$ $[\mathrm{A} / \mathrm{B}]<1,[[\mathrm{~A}-<. .>-\mathrm{B}]]^{\prime}=\mathrm{e}_{1}<[\mathrm{A} / \mathrm{B}]<\mathrm{e}_{4},[[\mathrm{~A} \mathrm{~B}]]$ $\mathrm{h}=\mathrm{A}-<\ldots \sim<\mathrm{B}$ if $\mathrm{e}_{5}<[\mathrm{A} / \mathrm{B}]<1$ and $[[\mathrm{A}-<\ldots>-$ $\mathrm{B}]]_{\mathrm{h}}{ }^{\prime}=\mathrm{e}_{1}<[\mathrm{A} / \mathrm{B}]<\mathrm{e}_{4}$.

\subsubsection{An example}

To demonstrate that our approach captures the essence of $\mathrm{O}[\mathrm{M}]$, we solve the heat exchanger example introduced by Mavrovouniotis and Stephanopoulos ${ }^{13}$. We have a countercurrent heat exchanger as pictured in Figure 9, with a hot flow that is cooled and a cold flow that is heated. The important parameters are the molar heat capacities of the hot and cold streams, $\mathrm{K}_{\mathrm{h}}$ and $\mathrm{K}_{\mathrm{c}}$ and the molar flows $F_{h}$ and $F_{c}$. The following temperature differences may be defined:

$$
\begin{array}{lll}
\text { ÌT }_{\mathrm{h}} & = & \mathrm{T}_{\mathrm{h} 1}-\mathrm{T}_{\mathrm{h} 2} \\
= & \mathrm{T}_{\mathrm{c} 1}-\mathrm{T}_{\mathrm{c} 2} \\
\mathrm{ÌT}_{1} & = & \mathrm{T}_{\mathrm{h} 1}-\mathrm{T}_{\mathrm{c} 1} \\
\text { Ì }_{2} & = & \mathrm{T}_{\mathrm{h} 2}-\mathrm{T}_{\mathrm{c} 2}
\end{array}
$$

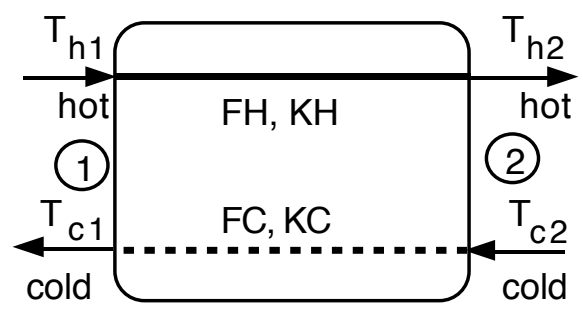




\section{Figure 9. A heat exchanger}

so that $\mathrm{IT}_{\mathrm{h}}$ is the drop in temperature of the hot stream, $\mathrm{IT}_{\mathrm{c}}$ the rise in temperature of the cold stream, and $\mathrm{IT}_{1}$ and $\mathrm{ItT}_{2}$ are the differences in temperature at either end of the exchanger. The definitions (4) constrain the values of the parameters:

$$
\mathrm{ÌT}_{\mathrm{h}}-\mathrm{ÌT}_{1}-\mathrm{ÌT}_{\mathrm{c}}+\mathrm{ÌT}_{2}=0
$$

and since all the energy entering the cold stream must come from the hot stream:

$$
\mathrm{İT}_{\mathrm{h}} \cdot \mathrm{K}_{\mathrm{h}} \cdot \mathrm{F}_{\mathrm{h}}=\mathrm{İT}_{\mathrm{c}} \cdot \mathrm{F}_{\mathrm{c}} \cdot \mathrm{K}_{\mathrm{c}}
$$

Following Mavrovouniotis and Stephanopoulos we will assume:

$$
\begin{array}{lll}
\mathrm{ÌT}_{2} & -< & \text { ÌT }_{1} \\
\mathrm{İT}_{1} & < & \text { ÌT }_{\mathrm{h}} \\
\mathrm{K}_{\mathrm{h}} & >\sim & \mathrm{K}_{\mathrm{c}}
\end{array}
$$

(a) Applying [[] ] ${ }_{\mathrm{h}}$ ' to (7) and (8) we get $\mathrm{ÌT}_{2} / \mathrm{ITT}_{1}=\left[\mathrm{e}_{1}\right.$, $\mathrm{e}_{6}$ ] and $\mathrm{IT}_{1} / \mathrm{IT}_{\mathrm{h}}<\mathrm{e}_{5}$. This simply yields $\mathrm{IT}_{2} / \mathrm{IT}_{\mathrm{h}}<\mathrm{e}_{1} \mathrm{e}_{5}$ $<\mathrm{e}_{1}$, and applying $[[]]_{\mathrm{h}}$ gives

$$
\text { İT }_{2} \quad<\quad \text { İT }_{\mathrm{h}}
$$

(b) From (5) we know that $\frac{\mathrm{It}_{\mathrm{c}}}{\mathrm{IT}_{\mathrm{h}}}=1-\frac{\mathrm{IT}_{1}}{\mathrm{IT}_{\mathrm{h}}}+\frac{\mathrm{IT}_{2}}{\mathrm{IT}_{\mathrm{h}}}$. Using [[ ] $]_{\mathrm{h}}$ ' on (8) and (10) we can rewrite this as $\mathrm{IT}_{\mathrm{c}}$ $/ \mathrm{IT}_{\mathrm{h}}=[1-\mathrm{e} /(1+\mathrm{e}), 1+\mathrm{e} /(1+\mathrm{e})]$. Clearly, since e $<1$, İT $_{\mathrm{c}} / \mathrm{ÌT}_{\mathrm{h}} /\left[\mathrm{e}_{2}, \mathrm{e}_{3}\right]$ so $[[]]_{\mathrm{h}}$ gives us :

$$
\text { İT }_{\mathrm{c}} \sim<\ldots>\sim \quad \mathrm{ItT}_{\mathrm{h}}
$$

(c) Applying [[ ] $]_{\mathrm{h}}$, to (8) and (11) we get $\mathrm{IT}_{\mathrm{c}} / \mathrm{IT}_{\mathrm{h}}=\left[\mathrm{e}_{2}\right.$, $\mathrm{e}_{3}$ ] and $\mathrm{ÌT}_{1} / \mathrm{IT}_{\mathrm{h}}<\mathrm{e}_{5}$. This gives us $\mathrm{IT}_{1} / \mathrm{ÌT}_{\mathrm{c}}<\mathrm{e}_{5}(1+\mathrm{e})<$ $\mathrm{e}_{1}$, and applying $[[]]_{\mathrm{h}}$ gives

$$
\text { İT }_{1} \quad<\quad \text { İT }_{\mathrm{c}}
$$

(d) Rewriting (6) as $\frac{\mathrm{IT}_{\mathrm{c}}}{\frac{\mathrm{IT}}{\mathrm{h}}}=1-\frac{\mathrm{IT}_{1}}{\mathrm{IT}_{\mathrm{h}}}+\frac{\mathrm{ItT}_{2}}{\mathrm{IT}_{\mathrm{h}}}$ and substituting in the results of applying $\left[[]_{\mathrm{h}}\right.$ ' to [9] and [11], we get $\mathrm{F}_{\mathrm{c}} / \mathrm{F}_{\mathrm{h}}=\left[\mathrm{e}_{2}, \mathrm{e}_{3}{ }^{2}\right]$ which by $[[]]_{\mathrm{h}}$ gives us:

$$
\mathrm{F}_{\mathrm{c}} \quad \sim<\ldots>\sim \mathrm{F}_{\mathrm{h}}
$$

These results are precisely those obtained by $\mathrm{O}[\mathrm{M}]$.

\subsection{The FOG approach}

In this section we consider how the interval methods introduced in Sections 3 may be used to model Raiman's 2 FOG. Raiman's approach may modelled by interpreting the relations $\mathrm{Vo}$, $\mathrm{Co}$ and $\mathrm{Ne}$ in terms of the basic relations supplied by $\mathrm{O}[\mathrm{M}]$. Mavrovouniotis and Stephanopoulos 3 suggest the equivalences:

$\begin{array}{lll}\text { A NeB } & - & \text { A }<<\text { B } \\ \text { A Vo B } & - & \text { A } \sim<. . .>\text { B } \\ \text { A Co B } & - & \text { A }-<\ldots>- \text { B }\end{array}$

in which case the technique we have discussed for $\mathrm{O}[\mathrm{M}]$ relations may be applied.

\subsubsection{An interval interpretation of FOG}

Alternatively we can adopt Raiman's definitions and obtain Vo and Co in terms of $\mathrm{Ne}$ :

$$
\begin{array}{lll}
\text { A Vo B } & \text { iff } & (\text { A - B ) Ne B } \\
\text { A Co B } & \text { iff } & \text { AC A Ne C } \Leftrightarrow \text { B Ne C }
\end{array}
$$

then borrowing from $\mathrm{O}[\mathrm{M}]$ and defining $\mathrm{Ne}$ by the ratio between $A=\left[a_{1}, a_{2}\right]$ and $B=\left[b_{1}, b_{2}\right]$, we have, say:

$\mathrm{ANe} B \quad$ iff $\quad[\mathrm{A} / \mathrm{B}]<\mathrm{e}_{5}$

since $A-B=\left[a_{1}-b_{2}, a_{2}-b_{1}\right],(14)$ and $A$ Vo B $\rightarrow B$ Vo A give us:

$$
\text { A Vo B iff } \frac{\mathrm{a}_{2}-\mathrm{b}_{1}}{\mathrm{~b}_{1}}<\mathrm{e}_{5} \text { and } \frac{\mathrm{b}_{2}-\mathrm{a}_{1}}{\mathrm{a}_{1}}<\mathrm{e}_{5}
$$

As far as Co is concerned, we know from (14) that for A Co B then for $C=\left[c_{1}, c_{2}\right]$ such that $a_{2} / c_{1}<e_{5}, b_{2} / c_{1}$ $<\mathrm{e}_{5}$. This condition alone does not preclude $\mathrm{A} \mathrm{Ne} B$, so we need to encode the intuitive notion that $\mathrm{A} / \mathrm{B}=[1-\mathrm{k}, 1$ $+\mathrm{k}] \pm 1$. We will conjecture these limits as $\mathrm{A} / \mathrm{B}=\left[1-\mathrm{e}_{2}\right.$, $1+\mathrm{e}_{2}$ ] so that:

$$
\text { A Co B } \quad \text { iff } \quad A=\left[\left(1-e_{2}\right) b_{2},\left(1+e_{2}\right) b_{1}\right]
$$

Since the intervals are bounded by real parameters derived from e which describes the granularity of the reasoning, both these approaches allow us to perform inferences that are not possible in FOG such as:

$$
\text { A Vo } 0.1, \text { B Vo } 1000 \quad \rightarrow \quad \text { A Ne B }
$$

\subsubsection{A further example}

Raiman provides a simple mechanics problem that defeats simple qualitative techniques as motivation for the development of FOG. Here we show how it may be solved using the interval schemes described above. Two masses $\mathrm{M}$ and $\mathrm{m}$ (Figure 10), where $\mathrm{m}$ is negligible in comparison with $\mathrm{M}$, and roughly equivalent speeds $\mathrm{V}_{\mathrm{i}}$ and $\mathrm{v}_{\mathrm{i}}$, are moving in opposite directions in one dimension. What happens after impact? 


\section{M}

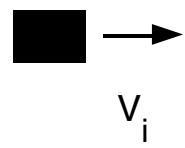

Figure 10. A pair of colliding masses

We have:

$\begin{array}{lll}\mathrm{m} & \mathrm{Ne} & \mathrm{M} \\ \mathrm{v}_{\mathrm{i}} & \mathrm{Vo} & -\mathrm{V}_{\mathrm{i}}\end{array}$

The conservation of energy and momentum give us, respectively:

$$
\begin{aligned}
& M V_{i}^{2}+m_{i}{ }^{2} V_{o} \quad M V_{f}^{2}+m_{f}{ }^{2} \\
& \mathrm{MV}_{\mathrm{i}}-\mathrm{mv}_{\mathrm{i}} \quad \mathrm{Vo} \quad \mathrm{MV}_{\mathrm{f}}+\mathrm{mv}_{\mathrm{f}}
\end{aligned}
$$

Using the $\mathrm{O}[\mathrm{M}]$ interpretations of $\mathrm{Ne}$ and Vo suggested by Mavrovouniotis and Stephanopoulos, and applying [[ ] $]_{\mathrm{h}}$, we can rewrite (19) and (20) as:

$$
\begin{aligned}
& \frac{v_{i}\left\{1-\frac{m_{i}^{2}}{M v_{i}^{2}}\right\}}{v_{f}\left\{1+\frac{m v_{f}^{2}}{M v_{f}^{2}}\right\}}=\left[e_{2}, e_{3}\right] \\
& \frac{v_{i}\left\{1-\frac{m v_{i}}{M v_{i}}\right\}}{v_{f}\left\{1+\frac{m v_{f}}{M v_{f}}\right\}}=\left[e_{2}, e_{3}\right]
\end{aligned}
$$

Now, (17) and (18) give us the values $\mathrm{m} / \mathrm{M}<\mathrm{e}_{5}$ and $\mathrm{v}_{\mathrm{i}} / \mathrm{V}_{\mathrm{i}}<\left[\mathrm{e}_{2}, \mathrm{e}_{3}\right]$, so, taking the accuracy parameter e to be 0.1 , we can solve (21) and (22) and calculate $\mathrm{V}_{\mathrm{f}}=[0.84$, 1.1] $\mathrm{V}_{\mathrm{i}}$, ignoring the physically impossible solution, so that:

$$
\mathrm{V}_{\mathrm{f}} \quad \mathrm{Vo}_{\mathrm{i}} \quad \mathrm{V}_{\mathrm{i}}
$$

Applying [[ ] $]_{\mathrm{h}}$ ' gives us $\mathrm{V}_{\mathrm{f}} / \mathrm{V}_{\mathrm{i}}=\left[\mathrm{e}_{2}, \mathrm{e}_{3}\right]$ which, along with (22) allows us to deduce:

$$
v_{\mathrm{f}} \quad \mathrm{Vo}_{\mathrm{f}} \quad \mathrm{v}_{\mathrm{f}}
$$

Comparing this with Raiman's results suggests that this interpretation of Vo is perhaps closer to his idea of Co than Vo.

Solving the problem with the second interpretation of the symbolic relations, we can rewrite (16) as:

$$
\text { A Vo B iff } \quad[A / B]=\left[\frac{1}{1+e_{5}}, 1+e_{5}\right]
$$

With $\mathrm{m} / \mathrm{M}<\mathrm{e}_{5}$ as before, we can solve (21) and (22) to get $\mathrm{V}_{\mathrm{f}}=[0.84,1.1] \mathrm{V}_{\mathrm{i}}$, so that:

$$
\begin{array}{lllllll}
\mathrm{V}_{\mathrm{f}} & \mathrm{Vo} & \mathrm{V}_{\mathrm{i}} & \text { and } & \mathrm{v}_{\mathrm{f}} & \mathrm{Vo}_{\mathrm{O}} & \mathrm{V}_{\mathrm{f}}
\end{array}
$$

\subsubsection{Related work}

In a recent paper Dubois and $\operatorname{Prade}^{8}$ suggest another means of dealing with Raiman's relations, providing a new semantics based on crisp intervals. Whereas our approach makes Raiman's inference rules redundant to some extent by propagating interval values and mapping between intervals and relations, Dubois and Prade augment the rules by parameterising the symbol relations with tolerance intervals into which the ratios of the related quantities fall:

$$
\mathrm{A} \operatorname{Vo}(\mathrm{M}) \mathrm{B} \Leftrightarrow 1-\mathrm{e} \leq \min (\mathrm{A} / \mathrm{B}, \mathrm{B} / \mathrm{A}) \leq 1
$$

where $\mathrm{M}=[1-\mathrm{e}, 1]$ and $0 \leq \mathrm{e} \leq 1$

As inference proceeds, the tolerance interval evolves, its growth depending on which rules are fired. The size of the interval can be used to terminate inference when a given limit is exceeded, rather than after an arbitrary number of steps.

\section{A MORE COMPLEX EXAMPLE}

In this section we consider the application of methods of order of magnitude reasoning based on interval analysis to a more complex problem, namely the steady state analysis of an anaerobic digestor. Such digestors form the basis of many sewage treatment facilities and thus represent an important class of bioreactor. Bailey and Ollis ${ }^{14}$ give discuss the model of an anaerobic digestor represented by the set of equations in Figure 11.

An analytical solution to this rather complex model may be obtained, but only if exact values of all the numerical constants are given. Using much less precise knowledge, it is possible to deduce quite a lot about the system's steady state behaviour using order of magnitude reasoning. In the following analysis we apply the style of reasoning introduced by Mavrovouniotis and Stephanopoulos using interval arithmetic as discussed in Section 4.2.

We start with an estimation of the rate $\mu$ based on the knowledge that, in the steady state, (hs) is roughly equal to $\mathrm{K}_{\mathrm{S}}$ but much smaller than $\mathrm{K}_{\mathrm{i}}$ :

$$
\begin{array}{ll}
\text { (hs) } & \sim<\ldots>\sim \mathrm{K}_{\mathrm{S}} \\
\text { (hs) } & <<\quad \mathrm{K}_{\mathrm{i}}
\end{array}
$$

Applying the mapping $[[]]_{\mathrm{h}}$ ' to $=(40)$ and (41) we know that $\frac{\mathrm{K}_{\mathrm{S}}}{(\mathrm{hs})}=\left[\mathrm{e}_{2}, \mathrm{e}_{3}\right]$ and $\frac{(\mathrm{hs})}{\mathrm{K}_{\mathrm{i}}}=\left[0, \mathrm{e}_{5}\right]$. Thus from (37) we have:

$$
\frac{\mu_{\max }}{\mu}=\left[1+\mathrm{e}_{2}, 1+\mathrm{e}_{3}+\mathrm{e}_{5}\right]
$$


If we take the accuracy parameter to be $\mathrm{e}=0.1$, we can see that $\frac{\mu_{\max }}{\mu}<\left[\mathrm{e}_{7}, \mathrm{e}_{4}\right]$ so that applying $[[]]_{\mathrm{h}}$ gives:

$$
\mu_{\max }>-\mu
$$

and we know that the rate is moderately smaller than the maximum. Next we can make an assessment of the rate of production of dissolved $\mathrm{CO}_{2},\left[\mathrm{CO}_{2}\right]_{\mathrm{D}}$. We start from the observation that the steady state concentration is much greater than the initial concentration, and slightly less than the equilibrium concentration:

$$
\begin{array}{lll}
{\left[\mathrm{CO}_{2}\right]_{\mathrm{D}}} & >> & {\left[\mathrm{CO}_{2}\right]_{\mathrm{D}_{0}}} \\
{\left[\mathrm{CO}_{2}\right]_{\mathrm{D}}} & \sim< & {\left[\mathrm{CO}_{2}\right]_{\mathrm{D}} *}
\end{array}
$$

Applying $[[]]_{\mathrm{h}}$ ' we learn that $\frac{\left[\mathrm{CO}_{2}\right]_{\mathrm{D}}}{\left[\mathrm{CO}_{2}\right]_{\mathrm{D}}{ }^{*}}=\left[1, \mathrm{e}_{3}\right]$ and $\frac{\left[\mathrm{CO}_{2}\right]_{\mathrm{D}_{0}}}{\left[\mathrm{CO}_{2}\right]_{\mathrm{D}}}=\left[0, \mathrm{e}_{5}\right]$. Using (42) in (33) we find that:

$$
\begin{aligned}
& \frac{\mathrm{d}\left[\mathrm{CO}_{2}\right]_{\mathrm{D}}}{\mathrm{dt}}=\frac{\mathrm{F}}{\mathrm{V}}\left(\left[-1, \mathrm{e}_{5}-1\right]\left[\mathrm{CO}_{2}\right]_{\mathrm{D}}\right) \\
& +\mathrm{T}_{\mathrm{G}}+\mathrm{R}_{\mathrm{B}}+\mathrm{R}_{\mathrm{C}}
\end{aligned}
$$

Now, from (43) and (30) we get:

$$
\mathrm{T}_{\mathrm{G}} \quad=\quad \mathrm{k}_{\mathrm{L}^{\mathrm{a}}}\left(\left[0, \mathrm{e}_{3}-1\right]\left[\mathrm{CO}_{2}\right]_{\mathrm{D}}\right)
$$

which allows us to rewrite (44) as:

$$
\begin{array}{ll}
\frac{\mathrm{d}\left[\mathrm{CO}_{2}\right]_{\mathrm{D}}}{\mathrm{dt}}=\quad\left[\mathrm{CO}_{2}\right]_{\mathrm{D}} \mathrm{k}_{\mathrm{L}} \mathrm{a}\left[0, \mathrm{e}_{3}-1\right] \\
\left.+\frac{\mathrm{F}}{\mathrm{V}}\left[-1, \mathrm{e}_{5}-1\right]\left[\mathrm{CO}_{2}\right]_{\mathrm{D}}\right] \\
+\mathrm{R}_{\mathrm{B}}+\mathrm{R}_{\mathrm{C}}
\end{array}
$$

Given the additional knowledge that :

$$
\mathrm{k}_{\mathrm{L}} \mathrm{a} \quad>\quad \frac{\mathrm{F}}{\mathrm{V}}
$$

we can apply $[[]]_{\mathrm{h}}$ ' to obtain $\frac{\mathrm{F}}{\mathrm{V}} / \mathrm{k}_{\mathrm{L}} \mathrm{a}=\left[0, \mathrm{e}_{5}\right]$ which we can use with (46) to learn that:

$$
\begin{gathered}
\frac{\mathrm{d}\left[\mathrm{CO}_{2}\right]_{\mathrm{D}}}{\mathrm{dt}}=\left[\mathrm{CO}_{2}\right]_{\mathrm{D}} \mathrm{k}_{\mathrm{L}} \mathrm{a}\left[0, \mathrm{e}_{3}+\mathrm{e}_{5}+\mathrm{e}_{5}{ }^{2}-1\right] \\
+\mathrm{R}_{\mathrm{B}}+\mathrm{R}_{\mathrm{C}}
\end{gathered}
$$

$$
\begin{aligned}
& \frac{\mathrm{dp}_{\mathrm{CO}_{2}}}{\mathrm{dt}} \quad=\quad-\mathrm{p}_{\mathrm{T}} \frac{\mathrm{V}}{\rho_{\mathrm{g}} \mathrm{V}_{\mathrm{G}}} \mathrm{T}_{\mathrm{G}}-\frac{\mathrm{p}_{\mathrm{CO}_{2}}}{\mathrm{~V}_{\mathrm{G}}} \mathrm{Q} \\
& \mathrm{Q}_{\mathrm{CO}_{2}} \quad=\quad-\frac{\mathrm{V}}{\rho_{\mathrm{g}}} \mathrm{T}_{\mathrm{G}} \\
& \mathrm{Q}=\mathrm{Q}_{\mathrm{CO}_{2}}+\mathrm{Q}_{\mathrm{CH}_{4}}+\mathrm{Q}_{\mathrm{H}_{2} \mathrm{O}} \\
& \text { (hs) } \quad=\quad \frac{\mathrm{s}\left(\mathrm{h}^{+}\right)}{\mathrm{K}_{\mathrm{a}}} \\
& \left(\mathrm{h}^{+}\right) \quad=\frac{\mathrm{K}_{1}\left[\mathrm{CO}_{2}\right]_{\mathrm{D}}}{\left[\mathrm{HCO}_{3}^{-}\right]} \\
& {\left[\mathrm{HCO}_{3}{ }^{-}\right]=\mathrm{z}-\mathrm{s}} \\
& \frac{\mathrm{d}}{\mathrm{dt}} \quad=\quad \frac{\mathrm{F}}{\mathrm{V}}\left(\mathrm{z}_{\mathrm{O}}-\mathrm{z}\right) \\
& \mathrm{T}_{\mathrm{G}} \quad=\quad \mathrm{k}_{\mathrm{L}} \mathrm{a}\left(\left[\mathrm{CO}_{2}\right]_{\mathrm{D}}{ }^{*}-\left[\mathrm{CO}_{2}\right]_{\mathrm{D}}\right) \\
& {\left[\mathrm{CO}_{2}\right]_{\mathrm{D}}^{*}=\mathrm{K}_{\mathrm{H}^{\mathrm{a}} \mathrm{P}_{\mathrm{CO}_{2}}}} \\
& \frac{\mathrm{d}[\text { tox }]}{\mathrm{dt}} \quad=\quad \frac{\mathrm{F}}{\mathrm{V}}\left([\text { tox }]_{0}-[\text { tox }]\right) \\
& \frac{\mathrm{d}\left[\mathrm{CO}_{2}\right]_{\mathrm{D}}}{\mathrm{dt}}=\frac{\mathrm{F}}{\mathrm{V}}\left(\left[\mathrm{CO}_{2}\right]_{\mathrm{D}_{0}}-\left[\mathrm{CO}_{2}\right]_{\mathrm{D}}\right)+\mathrm{T}_{\mathrm{G}}+\mathrm{R}_{\mathrm{B}}+\mathrm{R}_{\mathrm{C}}
\end{aligned}
$$




$$
\begin{array}{lll}
\mathbf{R}_{\mathrm{c}} & =\frac{\mathrm{F}}{\mathrm{V}}\left(\left[\mathrm{HCO}_{3}\right]_{0}-\left[\mathrm{HCO}_{3}{ }^{-}\right]\right)+\frac{\mathrm{ds}}{\mathrm{dt}}+\frac{\mathrm{dz}}{\mathrm{dt}} \\
\frac{\mathrm{dx}}{\mathrm{dt}} & =\frac{\mathrm{F}}{\mathrm{V}}\left(\mathrm{x}_{0}-\mathrm{x}\right)+\mu \mathrm{x}-\mathrm{k}_{\mathrm{T}}[\mathrm{tox}] \\
\frac{\mathrm{ds}}{\mathrm{dt}} & =\frac{\mathrm{F}}{\mathrm{V}}\left(\mathrm{s}_{0}-\mathrm{s}\right)-\frac{\mu}{\mathrm{Y}_{\mathrm{x} / \mathrm{s}}} \mathrm{x} \\
\mu & =\frac{\mu_{\mathrm{max}}}{\left[1+\frac{\mathrm{K}_{\mathrm{s}}}{(\mathrm{hs})}+\frac{(\mathrm{hs})}{\mathrm{K}_{\mathrm{i}}}\right]} \\
\mathbf{R}_{\mathrm{B}} & =\mathrm{Y}_{\mathrm{CO}_{2} / \mathrm{x}} \mu \mathrm{x} \\
\mathrm{Q}_{\mathrm{CH}_{4}} & =\frac{\mathrm{V}}{\rho_{\mathrm{g}}} \mathrm{Y}_{\mathrm{CH}_{4} / \mathrm{x}} \mu \mathrm{x}
\end{array}
$$

Figure 11. Equations describing an anaerobic digestor

Now, $\left[0, \mathrm{e}_{3}+\mathrm{e}_{5}+\mathrm{e}_{5}^{2}-1\right]<\left[0, \mathrm{e}_{3}\right]$, so applying [[ ]$_{\mathrm{h}}$ we get the fact that $\left[\mathrm{CO}_{2}\right]_{\mathrm{D}} \mathrm{k}_{\mathrm{L}} \mathrm{a}\left[0, \mathrm{e}_{3}+\mathrm{e}_{5}+\mathrm{e}_{5}{ }^{2}-\right.$ $1]<<\ldots<\left[\mathrm{CO}_{2}\right]_{\mathrm{D}} \mathrm{k}_{\mathrm{L}}$, so that:

$$
\frac{\mathrm{d}\left[\mathrm{CO}_{2}\right]_{\mathrm{D}}}{\mathrm{dt}}<<\ldots-<\left[\mathrm{CO}_{2}\right]_{\mathrm{D}} \mathrm{k}_{\mathrm{L}} \mathrm{a}+\mathrm{R}_{\mathrm{B}}+\mathrm{R}_{\mathrm{C}}
$$

and the effect of the mass transfer rate of $\mathrm{CO}_{2}$ from gas to liquid phase, $\mathrm{T}_{\mathrm{G}}$, can be seen to dominate in determining the instantaneous concentration of dissolved $\mathrm{CO}_{2}$. The original equation is already considerably simplified, and it can be simplified further. The relationship between the constant yield coefficients $\mathrm{Y}_{\mathrm{x} / \mathrm{s}}$ and $\mathrm{Y}_{\mathrm{CO}_{2} / \mathrm{x}}$ is such that:

$$
\frac{1}{\mathrm{Y}_{\mathrm{x} / \mathrm{s}}} \quad>\sim \quad \mathrm{Y}_{\mathrm{CO}_{2} / \mathrm{x}}
$$

so that, by [[ ] $]_{\mathrm{h}}, \frac{1}{\mathrm{Y}_{\mathrm{x} / \mathrm{s}} \cdot \mathrm{Y}_{\mathrm{CO}_{2} / \mathrm{x}}}=\left[1, \mathrm{e}_{3}\right]$. This allows us to rewrite (36) as:

$$
\begin{array}{ll}
\frac{\mathrm{ds}}{\mathrm{dt}} \quad=\quad \frac{\mathrm{F}}{\mathrm{V}}\left(\mathrm{s}_{0}-\mathrm{s}\right) \\
\\
\quad-\left[1, \mathrm{e}_{3}\right] \mathrm{Y}_{\mathrm{CO}_{2} / \mathrm{x}} \mu \mathrm{x}
\end{array}
$$

which may be combined with (38) to give:

$$
\begin{aligned}
\frac{\mathrm{ds}}{\mathrm{dt}}+\mathrm{R}_{\mathrm{B}}= & \frac{\mathrm{F}}{\mathrm{V}}\left(\mathrm{s}_{0}-\mathrm{s}\right) \\
& -\left[0, \mathrm{e}_{3}-1\right] \mathrm{Y}_{\mathrm{CO}_{2} / \mathrm{x}} \mu \mathrm{x}
\end{aligned}
$$

Now, since the substrate concentration is much less than its initial value:

$$
\mathrm{s} \quad \quad<\quad \mathrm{s}_{0}
$$

we have $\mathrm{s}=\left[0, \mathrm{e}_{5}\right] \mathrm{s}_{0}$ from $[[]]_{\mathrm{h}}$, and:

$$
\begin{aligned}
\frac{\mathrm{ds}}{\mathrm{dt}}+\mathrm{R}_{\mathrm{B}} \quad=\quad\left[1-\mathrm{e}_{5}, 1\right] \frac{\mathrm{F}}{\mathrm{V}} \mathrm{s}_{0} \\
\\
-\left[0, \mathrm{e}_{3}-1\right] \mathrm{Y}_{\mathrm{CO}_{2} / \mathrm{x}} \mu \mathrm{x}
\end{aligned}
$$

which with the additional knowledge that $\mathrm{Y}_{\mathrm{CO}_{2} / \mathrm{x}} \mu \mathrm{x}=[0$, $\left.\mathrm{e}_{5}\right] \frac{\mathrm{F}}{\mathrm{V}} \mathrm{s}_{0}$, which comes from applying [[ ] ] ${ }_{\mathrm{h}}$, to $\mathrm{Y}_{\mathrm{CO}_{2} / \mathrm{x}}$ $\mu \mathrm{x}<<\frac{\mathrm{F}}{\mathrm{V}} \mathrm{s}_{0}$, we can write:

$$
\frac{\mathrm{ds}}{\mathrm{dt}}+\mathrm{R}_{\mathrm{B}} \quad=\quad\left[1-\mathrm{e}_{3} \mathrm{e}_{5}, 1\right] \frac{\mathrm{F}}{\mathrm{V}} \mathrm{s}_{0}
$$

Now, since we know that in the steady state $\mathrm{z}=\mathrm{z}_{0}$, (29) gives $\frac{\mathrm{d}}{\mathrm{dt}}=0$, and when we use the fact that the initial carbonate concentration is zero, $\left[\mathrm{HCO}_{3}{ }^{-}\right]_{0}=0$, we can rewrite (34) as:

$$
\mathrm{R}_{\mathrm{c}} \quad=\quad-\frac{\mathrm{F}}{\mathrm{V}}\left[\mathrm{HCO}_{3}^{-}\right]+\frac{\mathrm{ds}}{\mathrm{dt}}
$$

This in turn may be used with (51) to write (46) as:

$$
\begin{aligned}
\frac{\mathrm{d}\left[\mathrm{CO}_{2}\right]_{\mathrm{D}}}{\mathrm{dt}}=\left[\mathrm{CO}_{2}\right]_{\mathrm{D}} \mathrm{k}_{\mathrm{L}} \mathrm{a}\left[0, \mathrm{e}_{3}+\mathrm{e}_{5}+\mathrm{e}_{5}{ }^{2}-1\right] \\
+\left[1-\mathrm{e}_{3} \mathrm{e}_{5}, 1\right] \frac{\mathrm{F}}{\mathrm{V}} \mathrm{s}_{0} \\
-\frac{\mathrm{F}}{\mathrm{V}}\left[\mathrm{HCO}_{3}{ }^{-}\right]
\end{aligned}
$$

We also know that the carbonate concentration is moderately less than the initial substrate concentration, so 
that $\left[\mathrm{HCO}_{3}^{-}\right]-<\mathrm{s}_{0}$ and $[[]]_{\mathrm{h}}$ ' gives $\left[\mathrm{HCO}_{3}{ }^{-}\right]=\left[\mathrm{e}_{1}\right.$, $\left.\mathrm{e}_{6}\right] \mathrm{s}_{0}$. Thus:

$$
\begin{aligned}
\frac{\mathrm{d}\left[\mathrm{CO}_{2}\right]_{\mathrm{D}}}{\mathrm{dt}}=[ & {\left[\mathrm{CO}_{2}\right]_{\mathrm{D}} \mathrm{k}_{\mathrm{L}} \mathrm{a}\left[0, \mathrm{e}_{3}+\mathrm{e}_{5}+\mathrm{e} 5^{2}-1\right] } \\
& +\left[1-\mathrm{e}_{3} \mathrm{e}_{5}-\mathrm{e}_{6}, 1-\mathrm{e}_{1}\right] \frac{\mathrm{F}}{\mathrm{V}} \mathrm{s}_{0}
\end{aligned}
$$

which, using $[[]]_{\mathrm{h}}$, may be transformed into:

$$
\frac{\mathrm{d}\left[\mathrm{CO}_{2}\right]_{\mathrm{D}}}{\mathrm{dt}} \quad \leq \quad\left[\mathrm{CO}_{2}\right]_{\mathrm{D}} \mathrm{k}_{\mathrm{L}}^{\mathrm{a}}+\frac{\mathrm{F}}{\mathrm{V}} \mathrm{s}_{0}
$$

It is also possible to reason about the rate of change of the partial pressure of $\mathrm{CO}_{2}$, simplifying (23). We start by combining (24), (25) and (39) to get:

$$
\mathrm{Q}=-\frac{\mathrm{V}}{\rho_{\mathrm{g}}} \mathrm{T}_{\mathrm{G}}+\frac{\mathrm{V}}{\rho_{\mathrm{g}}} \mathrm{Y}_{\mathrm{CH}_{4} / \mathrm{x}} \mu \mathrm{x}+\mathrm{Q}_{\mathrm{H}_{2} \mathrm{O}}
$$

Using $[[]]_{\mathrm{h}}$ ' on the information that:

$$
\mathrm{T}_{\mathrm{G}} \quad-<\quad \mathrm{Y}_{\mathrm{CH}_{4} / \mathrm{x}} \mu \mathrm{x}
$$

we obtain $\mathrm{Y}_{\mathrm{CH}_{4} / \mathrm{x}} \mathrm{mx}=\left[\mathrm{e}_{7}, \mathrm{e}_{4}\right] \mathrm{T}_{\mathrm{G}}$. This allows us to write (52) as:

\section{FUTURE WORK}

The work described in this paper provides a sound theoretical basis for modelling order of magnitude reasoning using interval algebras. The next stage of this work is to implement a system that performs order of magnitude reasoning in this way. The goal of this new work is an interactive system that, given a set of equations relating one set of variables to another, and a number of order of magnitude relations between the variables, can use the methods described in Section 4 to establish relations between the magnitudes of previously unrelated variables.

\section{CONCLUSION}

We have demonstrated that, despite its simplicity, interval analysis, and the interval algebras that may be built using the techniques of interval analysis, are subtle and powerful enough to provide an underlying computational basis for several different types of system of order of magnitude reasoning. We can build a set of absolute intervals, defined by means of intuitive landmark values, that fall into a natural hierarchy of intervals of varying discrimination. These can form the basis of a reasoning system whose precision can be altered as desired. Such a system may be used for simple order of magnitude computations of the form $100+0.5 \pm 100$ in the manner of that of Dubois and Prade 4 , or as the basis for a scheme for reasoning about variables and constants which is essentially an extension

$$
\mathrm{Q}=\frac{\mathrm{V}}{\rho_{\mathrm{g}}}\left[\mathrm{e}_{7}-1, \mathrm{e}_{4}-1\right] \mathrm{T}_{\mathrm{G}}+\mathrm{Q}_{\mathrm{H}_{2} \mathrm{O}}
$$

and this may be substituted into (23) to obtain:

$$
\begin{aligned}
\frac{\mathrm{dp}_{\mathrm{CO}_{2}}}{\mathrm{dt}}=- & \mathrm{p}_{\mathrm{T}} \frac{\mathrm{V}}{\rho_{\mathrm{g}} \mathrm{V}_{\mathrm{G}}} \mathrm{T}_{\mathrm{G}} \\
& -\frac{\mathrm{p}_{\mathrm{CO}_{2}}}{\mathrm{~V}_{\mathrm{G}}}\left[\mathrm{Q}_{\mathrm{H}_{2} \mathrm{O}}+\frac{\mathrm{V}}{\rho_{\mathrm{g}}}\left[\mathrm{e}_{7}-1, \mathrm{e}_{4}-1\right] \mathrm{T}_{\mathrm{G}}\right]
\end{aligned}
$$

we know that $\mathrm{p}_{\mathrm{T}}$ is moderately larger than the partial pressure of $\mathrm{CO}_{2}$ so that:

$$
\mathrm{p}_{\mathrm{T}} \quad>-\quad \mathrm{p}_{\mathrm{CO}_{2}}
$$

so $\mathrm{p}_{\mathrm{T}}=\left[\mathrm{e}_{7}, \mathrm{e}_{4}\right] \mathrm{p}_{\mathrm{CO}_{2}}$ and we have:

$$
\frac{\mathrm{dp}_{\mathrm{CO}_{2}}}{\mathrm{dt}} \quad=\quad-\frac{\mathrm{pCO}_{2}}{\mathrm{~V}_{\mathrm{G}}}\left[\frac{\mathrm{V}}{\rho_{\mathrm{g}}} \mathrm{T}_{\mathrm{G}}+\mathrm{Q}_{\mathrm{H}_{2} \mathrm{O}}\right]
$$

which is considerably simpler than the original. So the use of interval algebras has provided us with a computationally easy means of simplifying quite complex expressions by taking into account information about the relative magnitude of variables in a way similar to that in which a human being might.

of Raiman's ${ }^{2}$ system that incorporates numerical information. An alternative scheme can be constructed across a ratio scale so that a given interval represents the range of values of the ratio between two quantities. This set of values can be used to reason about the relationship between quantities, forming the underlying mechanism of another type of order of magnitude reasoning. This allows the modelling of the approach adopted by Mavrovouniotis and Stephanopoulos ${ }^{3}$, as well as another means of modelling Raiman's treatment.

This approach to modelling order of magnitude reasoning has been illustrated on a number of examples, including the simplification of the steady state model of an anaerobic fermentor. Here several complex expressions were considerably simplified by eliminating negligible terms in a way analogous to that in which human beings perform the same task. There is, to my knowledge, no alternative system which could perform this kind of reasoning, making simplifications based on knowledge such as " $\mathrm{p}_{\mathrm{T}}$ is quite a lot larger than $\mathrm{p}_{\mathrm{CO}_{2}}$ " that is based on as simple an idea as interval arithmetic, and one that is as easy to implement. Other approaches either require more data, as conventional models do, or are based on complex ssytems of symbolic manipulation 2,3 .

\section{ACKNOWLEDGEMENTS}

This work was supported by a grant from ESPRIT Basic Research Action 3085 DRUMS, Defeasible Reasoning 
and Uncertainty Management Systems. Thanks, as ever, to all my colleagues on the project for continual help and encouragement. Particular thanks to Mirko Dohnal for suggesting semiqualitative reasoning, Henri Prade for timely advice, and to Didier Dubois and Louise TravéMassuyès for supplying papers.

\section{REFERENCES}

1. Bobrow, D., G. Qualitative Reasoning about Physical Systems, Elsevier Science Publishers B. V., Amsterdam, 1984.

2. Raiman O Order of magnitude reasoning, Proc. 5th National Conf. on Artificial Intelligence (AAAI 1986), Philadelphia, PA, pp 100-104, 1986.

3. Mavrovouniotis, M., L., and Stephanopoulos, G. Reasoning with orders of magnitude and approximate relations, Proc. 6th National Conf. on Artificial Intelligence (AAAI 1987), Seattle, WA, pp 626-630, 1987.

4. Dubois, D., and Prade, H. Fuzzy arithmetic in qualitative reasoning. In: Modelling and Control or Systems in Engineering, Quantum Mechanics, Economics and Biosciences (A. Blaqière ed.), Springer Verlag, Berlin, pp 457-467. 1989.

5. Travé-Massuyès, L., and Piera, N. The orders of magnitude models as qualitative algebras. Proc. 11th Inter. Joint Conf. on Artificial Intelligence (IJCAI 1989), Detroit Michigan, pp 12611266, 1989.

6. Struss, P. Mathematical aspects of qualitative reasoning, Artificial Intelligence in Engineering, 3, pp 156-169. 1988.

7. Moore, R. E., Interval Analysis. Prentice-Hall, Inc. Englewood Cliffs, N.J. 1966.

8. Dubois, D., and Prade, H. Semantic considerations on order of magnitude reasoning, Proc. IMACS workshop on Qualitative Reasoning and Decision Support Systems, Toulouse, March 1991.

9. Parsons, S. and Dohnal, M. Qualitative, semiqualitative and interval algebras. Technical Report, Dept Elec. Eng. Queen Mary and Westfield College, 1991.

10. Koivisto, R., Dohnal,M., and Likitalo, A. Deep and shallow knowledge integration: a case study of an AI diagnosis of a chemical reactor, The Second Scandinavian Conference on Artificial Intelligence, Tampere, 1989.

11. Dohnal, M. Naive Models as Active Expert Systems. In Bioengineering and Chemical Engineering, Coll. Czech. Chem. Comm., vol.53,1476-1499, 1988

12. Parsons, S. Qualitative and semiqualitative methods for integrating uncertainty handling formalisms. Technical Report, Dept Elec. Eng. Queen Mary and Westfield College, 1990.

13. Mavrovouniotis, M., L., and Stephanopoulos, G. Order-ofmagnitude reasoning with $\mathrm{O}[\mathrm{M}]$, Artificial Intelligence in Engineering, 4, pp 106-114, 1989.

14. Bailey, J. E. and Ollis, D. F. Biochemical Engineering Fundamentals. McGraw Hill, New York. (1977) 